\title{
Sobre a tradução de Oublieuse mémoire, de Jules Supervielle
}

Marlova G. Aseff

Resumo: Este artigo comenta a experiência da tradução de três sonetos e um quarteto do poeta franco-uruguaio Jules Supervielle (1884-1960) para a língua portuguesa. Trata-se da antologia Oublieuse mémoire, publicada em 1949, e pela qual o poeta recebeu o Prix des Critiques na França. O estudo e a tradução da poesia de Supervielle no Brasil assumem maior importância na atualidade, visto que sua obra influenciou Carlos Drummond de Andrade, conforme depoimento do próprio poeta divulgado em estudo de John Gledson (2003). Além disso, os poemas trazem interessantes reflexões sobre a memória, tema que atraiu inúmeros intelectuais no século 20, como Walter Benjamin, Henri Bergson e Marcel Proust, entre outros.

Palavras-chave: Jules Supervielle; tradução comentada; poesia; memória

\section{Por que traduzir Jules Supervielle}

Em Influências e impasses, John Gledson resgata a importância do poeta franco-uruguaio Jules Supervielle na obra do poeta brasileiro Carlos Drummond de Andrade. Mas quem é, afinal, esse poeta pouco conhecido no Brasil e que, conforme sustenta Gledson, teve influência tão "fascinante" sobre a poesia de Drummond? Super- 
vielle (1884-1960) foi narrador, dramaturgo e, acima de tudo, autor de uma poesia de estilo muito pessoal. Nasceu em Montevidéu, em uma família francesa ligada ao ramo financeiro. Com oito meses de idade ficou órfão. Criado pelos tios, aos 10 anos foi enviado à França para estudar. Passou a vida entre a Europa e a América do Sul e, juntamente com Jules Laforgue e Isidore Ducasse, forma a conhecida "trinca dos poetas franco-uruguaios". No entanto, Supervielle foi o único desses três a evocar em sua obra a vida no continente americano.

Para Gledson, Drummond sentiu-se atraído por Supervielle devido "à sua gaucherie partilhada" (GLEDSON, 2003, p. 97). Ou seja, ambos sofreriam de certa "inadequação social" por estarem "em uma posição intermediária entre o mundo da imaginação e o subconsciente, por um lado, e o entendimento do público, por outro" (Ibidem, p. 101). Sobre a preocupação de que sua poesia fosse compreendida por todos, Supervielle deixou o seguinte depoimento:

Pour moi ce n'est qu'à force de simplicité et de transparence que je parviens à aborder mes secrets essentiels et à décanter ma poésie profonde. Tendre à ce que le surnaturel devienne naturel et coule de source (ou en ait l'air). Faire en sorte que $l^{\prime}$ ineffable nous devienne familier tout en gardant ses racines fabuleuses. [...] Je n'ai guère connu la peur de la banalité qui hante la plupart des écrivains mais bien plutôt celle de l'incompréhension et de la singularité. N'écrivant pas pour des spécialistes du mystère j'ai toujours souffert quand une personne sensible ne comprenait pas un de mes poèmes ${ }^{1}(\mathrm{SU}-$ PERVIELLE 1951, p. 60-61).

\footnotetext{
Para mim, é somente pela simplicidade e pela transparência que consigo abordar os meus segredos essenciais e decantar a minha poesia profunda. Tendo a que o sobrenatural se torne natural e transpareça (ou tenha ares de transparência). Faço de modo que o inefável se torne familiar, ao mesmo tempo em que guarda as suas raízes fabulosas. [...] Não conheci o medo da banalidade que assombra a maior parte dos escritores, antes, conheci o medo da incompreensão e da singularidade. Como não escrevo para os
} 
Em seu estudo, Gledson resgata um tributo publicado por Drummond por ocasião da morte do poeta franco-uruguaio, no qual Drummond revela profunda devoção por Supervielle:

Não conheci pessoalmente Jules Supervielle, nunca recebi dele uma linha. Entretanto, sinto sua morte como a de um amigo chegado. A explicação é simples, amo sua poesia há mais de trinta anos, e relações desta natureza criam uma espécie de intimidade, que não depende de conhecimento individual. [....] Sua poesia tinha algo de muito especial, mas indefinível à primeira vista ou à luz das idéias estéticas em voga. Era canção melodiosa, mas discreta, de um homem que aprofundava sua condição de homem, e tentava mergulhar na essência da natureza, surdamente, suavemente, como quem vai de leve e devagar por uma estrada cada vez mais estreita, mais escura - estrada que tanto pode conduzir a uma floresta, como a um reino submarino, a uma paisagem pré-histórica, ou, quem sabe, a um universo gasoso (Drummond apud GLEDSON 2003:93).

Tal relação entre Supervielle e Drummond faz com que a poesia de Supervielle revista-se de um novo significado tanto para a crítica como para o público brasileiro. No entanto, sua produção poética não chegou ao Brasil em traduções. ${ }^{2}$ Pela antologia Oublieuse mémoire, publicada em 1949, Supervielle recebeu o Prix des Critiques e, em 1955, foi contemplado com o prêmio da Academia Francesa pelo conjunto da obra. Le corps tragique, espécie de meditação sobre a morte, publicada em 1959, foi seu último trabalho. Supervielle morreu em Paris em 1960, aos 76 anos.

especialistas em mistério, sempre sofri quando uma pessoa sensível não compreendia um dos meus poemas. (Tr. da autora)

2 A única tradução para o português brasileiro no Index Translationum database da Unesco é O boi e o jumento do presépio [Le boeuf et l'ane de la creche], por Abgar Renault (Belo Horizonte: Mazza, 1995). 
Marlova G. Aseff. Sobre a tradução de Oublieuse mémoire, de Jules Supervielle

Em seus primeiros poemas, o franco-uruguaio adotou formas tradicionais, passeando por influências parnasianas, simbolistas e também do modernista Rubén Darío (como em Brumes du passé, de 1900, e Comme des voiliers, de 1910). A proximidade a Jules Laforgue o ensinou a cultivar o humor, o que resultou na antologia Poèmes de l'humour triste, de 1919. Mas é somente a partir de Débarcadères (1922) que ele começa a se libertar das antigas influências, escrevendo a primeira de suas antologias em verso livre. Nela, se percebe o gosto pelas viagens que costumava fazer em companhia de Valery Larbaud (1881-1957), francês que popularizou os diários de viagem. Nessa antologia há, inclusive, um poema intitulado "L'escale brésilienne" ["A escala brasileira"]. O poeta esteve no Brasil diversas vezes. Em 1930, visitou cidades mineiras numa viagem que ficou registrada no relato autobiográfico Boire à la source. Depois de escrever um romance fantástico (L'homme de la pampa, 1923), Supervielle principia a exploração de aspectos mais profundos da sua personalidade em Gravitations (1925), Le forçat innocent (1930), Les amis inconnus (1934), La fable du monde (1938). Publicou também narrativas, como Premiers pas de l'univers e L'enfant de la haute mer. Para o teatro, escreveu peças como La belle au bois e Le voleur d'enfants. Amigo de Rainer Maria Rilke, com quem se correspondia regularmente, de Henri Michaux e de Jean Paulhan, incentivador da obra do uruguaio Felisberto Hernández, frequentador do atelier de Tarsila do Amaral durante as temporadas da pintora em Paris, Supervielle era uma figura intrigante; manteve-se independente dos movimentos literários do início do século passado, principalmente do surrealismo, muito difundido após o manifesto de André Breton, em 1924.

Zum Felde (apud BRANDO, 2001, p. 267), afirma que "dentro de um sóbrio equilíbrio convergem em sua poesia a imagem criacionista do surrealismo, a emotividade lírica e a nudez construtiva da forma, desprovida de todo luxo decorativo". Alguns temas recorrentes em sua poesia são os fantasmas do inconsciente, a presença escondida de Deus, a angústia perante a morte, jogos sutis com a linguagem, além dos lapsos da memória. Mas deixemos que 
o próprio poeta fale do que podemos encontrar em seu poema (SUPERVIELLE, 1938, p. 108).

Allons, mettez-vous là au milieu de mon poème [...]

Vous y trouverez un air, un ciel plus cléments que l'autre,

Dans un grand imprévu d'arbres ignorés par les saisons,

Une attentive floraison comme aux premiers jours du monde ${ }^{3}$.

\section{A antologia Oublieuse mémoire}

Pouco antes de a Segunda Guerra Mundial estourar, em outubro de 1939, Supervielle embarcou da França para o Uruguai com o objetivo de ali permanecer por três meses. O conflito transformou esses três meses em sete longos anos. Retornou à França somente em 1946 com o sentimento de que as mudanças trazidas pela guerra eram irremediáveis. Oublieuse mémoire pode ser compreendido como fruto dessas sensações, uma forma de resgatar o "eu" do poeta e de refazer seu próprio mundo. No entanto, como poderíamos imaginar inicialmente, não são poemas nostálgicos.

No âmbito da variada obra de Supervielle, a opção por traduzir o conjunto de quatro poemas que abrem a antologia Oublieuse mémoire (o volume constitui-se de 53 poemas, dividido em 14 partes) está baseada em três motivos: são poemas de sua maturidade poética; a antologia foi bem acolhida pela crítica da época e, finalmente, o tema abordado permeia a obra do poeta e também marcou a literatura do século passado. A memória foi uma questão que mobilizou a reflexão de diversos intelectuais e artistas no século 20. De Henri Bergson, em Matéria e memória, a Walter Benjamin, em Sobre alguns temas em Baudelaire, passando pelo conjunto da obra de Marcel

\footnotetext{
Vamos, entre no meio do meu poema [...]

Você encontrará um ar, um céu, mais clementes do que o outro,

Num grande imprevisto de árvores ignoradas pelas estações,

Uma atenta floração como nos primeiros dias do mundo. (Tradução da autora)
}

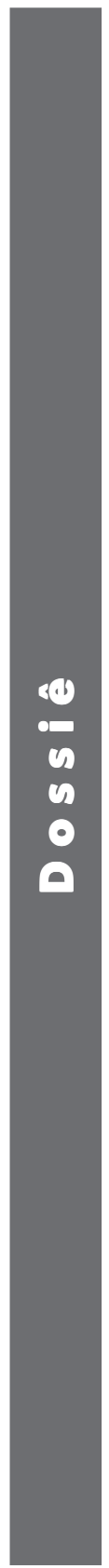


Proust e parte da criação de Felisberto Hernández, muitos foram o que se dedicaram a pensar nos mecanismos pelos quais a estrutura da memória influencia a experiência e de como é representada. $\mathrm{Na}$ obra de Supervielle, a reflexão sobre o passado, as origens e a memória em si mesma foi substrato para muitas de suas criações. A propósito da memória na obra de Supervielle, Blanchot (1960, p. 747) escreveu que "l'oubli est la vigilance même de la mémoire, la puissance gardienne grâce à laquelle se préserve le caché des choses et grâce à laquelle les hommes [...] reposent dans le caché d'eux-mêmes"

\section{Do soneto e do verso alexandrino}

Em Oublieuse mémoire, Supervielle abre o volume com três sonetos ingleses, conhecidos como isabelinos, seguidos por um poema de três quartetos. ${ }^{5} \mathrm{O}$ soneto inglês, por sua vez, é formado por três quartetos, cujas rimas podem variar, e um dístico também rimado. No que tange à métrica são alexandrinos - o verso francês por excelência. $\mathrm{O}$ alexandrino típico tem doze sílabas poéticas, divididas em duas partes iguais. Cada um desses hexassílabos é chamado de hemistíquio. Além disso, deve ser sempre acentuada a sexta sílaba. Quanto à tradição dessa métrica na poesia francesa, sabe-se que o alexandrino aparece na canção de gesta do século 12, voltando a ser usado naquele país no século 16, quando se firmou como o verso francês mais disseminado. Já o soneto, originário da Itália, chegou à poesia francesa no século 16. O sucesso dessa forma manteve-se até o século seguinte, tendo decaído no século 18 e voltado com força no século $19 .{ }^{6}$

Em português, a forma mais comum do soneto é o italiano. Costuma ter versos decassílabos e rimas do tipo ABBA/ABBA nos

\footnotetext{
4 “o esquecimento é a própria vigilância da memória, o poder guardião graças ao qual é preservado o lado oculto das coisas e graças ao qual os homens [...] repousam no segredo de si mesmos". (Tr. da autora)

5 A antologia privilegia certa regularidade quanto ao plano da métrica, embora haja alguns poemas em verso livre.

6 Ver Petit traité de versification française, p. 42.
} 
quartetos e CDC/CDC nos tercetos, conforme a forma fixada por Luís de Camões. Depois do decassílabo, o tipo de verso mais comum no soneto em língua portuguesa é o alexandrino, métrica essa que foi bastante usada na literatura brasileira por Olavo Bilac e por seus colegas parnasianos. Ou seja, a tradição da literatura brasileira aceita tanto o soneto quanto o verso alexandrino. Por isso, a escolha na tradução foi a de manter a forma do soneto, o esquema de rimas e a métrica. Ao manter as características formais, foi levado em conta o fato de que certamente não foi por acaso que Supervielle escolheu a forma fixa, afinal, esta é a única antologia que o poeta abre com um soneto inglês.

Contudo, a opção de manter essas características do original traria dificuldades. A primeira delas se deve ao fato de que no francês o léxico é formado basicamente por palavras oxítonas, o que não ocorre no português. Ou seja, há dificuldade para traduzir os versos como alexandrinos típicos, com a sexta sílaba acentuada, mantendo doze sílabas poéticas e cesura depois da sexta. Alguns autores não admitem como alexandrinos versos de doze sílabas que não sejam acentuados na sexta. Esses seriam simplesmente dodecassílabos. No entanto, modificações introduzidas pelo romantismo abriram a possibilidade de o alexandrino ser acentuado em outras sílabas. Dado o impasse, cogitei a possibilidade de verter os poemas para decassílabos, métrica tradicional do português, porém, com acentuação na $5^{\mathrm{a}}, 7^{\mathrm{a}}$ (ou $8^{\mathrm{a}}$ ) e na $10^{\mathrm{a}}$ sílabas. No entanto, essa opção foi descartada, pois cada verso de Supervielle traz muitas informações, e essa métrica engessaria o poema, além de perder a característica do ritmo bem marcado pela cesura depois da sexta sílaba. Cunha (1985) afirma que, na forma medieval, a sexta sílaba acentuada podia ser seguida de uma não acentuada, que não se contava na medida do verso, formando alexandrinos com treze sílabas. Ele sustenta que sendo o espanhol e o galego-português línguas em que predominam as paroxítonas, é natural que servisse de modelo o alexandrino de 13 sílabas, forma ainda usual do verso no primeiro desses idiomas (p. 672).

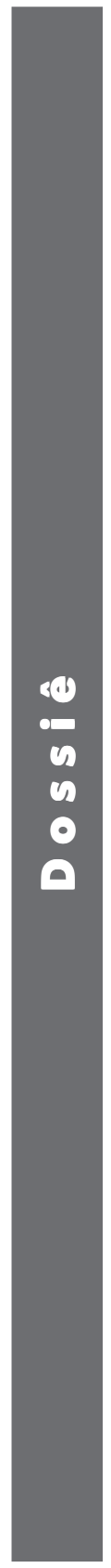


Marlova G. Aseff. Sobre a tradução de Oublieuse mémoire, de Jules Supervielle

Ou seja, a dificuldade encontrada durante o processo da tradução é algo inerente ao idioma, problema esse percebido ainda na Alta Idade Média pelos poetas de língua espanhola e galego-portuguesa. Segundo Cunha, "esse tipo de alexandrino com 13 sílabas (ou mais) foi empregado em todo o domínio românico, e as Cantigas de Santa Maria, do rei Afonso X, o Sábio, dão-nos prova de sua utilização na literatura galego-portuguesa" (Ibid.). A decisão, então, foi a de traduzir os sonetos mantendo a métrica em alexandrinos, porém sem contar a sílaba que está após a sexta acentuada, quando essa existisse. A regra que no português serve para o final dos versos, de só escandir o verso até a última sílaba tônica, vale, então, também para o final do primeiro hemistíquio. Buscando nos poemas de Bilac, encontram-se exemplos de como ele também procedeu dessa forma, como no verso “Co/mo/ de/pois/ do/ so/nho, // é/ tris/te a/ rea/li/da/de". ${ }^{7}$

\section{Os poemas}

O soneto isabelino privilegia o desenvolvimento de uma lógica em três etapas e é encerrado com um dístico que, no caso específico dos sonetos analisados, servem todos os três como diálogos com a memória. Pode-se questionar por que motivo o poeta privilegiou a forma fixa do soneto, já que, como se viu, não era o usual em sua obra. É possível supor que Supervielle quisesse que o próprio poema pudesse ser memorizado, razão que está na própria gênese do gênero lírico. Outra razão estaria ligada ao fenômeno do paralelismo usado como recurso em algumas estrofes. No plano morfossintático predomina o estilo verbal, que confere aos poemas vários movimentos, ora antagônicos, ora fluidos e mutantes. Como bem observa Roy (1953, p. 44), Supervielle é um poeta "sensível aos acordes, aos ritmos e às imagens, ao paralelismo de forças e movimentos".

Este verso pertence ao poema "Sonho". A elisão entre "sonho" e o "é" não é possível pois o "é" é uma vogal átona. 
A memória, por sua vez, é qualificada como "leve", "confusa" e "irmã obscura". Outras palavras recorrentes na obra de Supervielle merecem ser destacadas, como rose [rosa] (sinônimo de poema), oiseau [pássaro], abeille [abelha], além de vocábulos como museau [focinho], que reforçam o zoomorfismo muito presente em seus poemas. Source [fonte ou nascente] é também uma palavra muito cara a ele, pois os pais do poeta morreram ao beber água contaminada (GLEDSON, 2003, p. 107).

A seguir, são analisados os três sonetos mais os quartetos finais com uma abordagem que não busca separar em territórios estanques a forma e o conteúdo. A primeira questão surgiu já com o título: a palavra oublieuse significa "que esquece deliberadamente". A primeira escolha foi usar "memória olvidante", embora não exista esse segundo termo na língua portuguesa. Cogitou-se também "memória negligente", "ingrata", "distraída", "olvidadiça" ou "esquecidiça". No entanto, para evitar que o título ficasse com o registro acima do original, a opção foi por "Memória infiel".

\section{Soneto I}

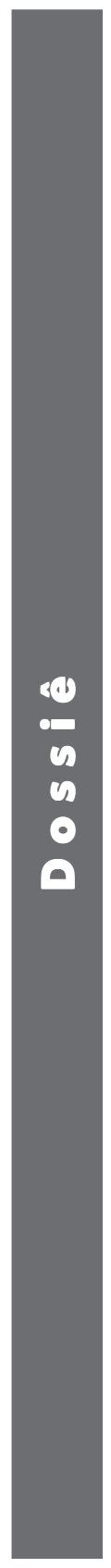

Pâle soleil d'oubli, lune de la mémoire, Que draines-tu au fond de tes sourdes contrées? Est-ce donc là ce peu que tu donnes à boire Ces gouttes d'eau, le vin que je te confiai?

A primeira estrofe do primeiro soneto apresenta uma espécie de protesto ou de provocação à memória e, consequentemente, ao esquecimento. É formada por dois questionamentos retóricos que demonstram que, para o poeta, o que a memória tem a oferecer é insuficiente, pois apenas parte da experiência é levada até seus "surdos domínios". O sol do esquecimento é pálido, fraco: não aquece. E as lembranças não matam a sede de quem recorda. Quanto à métri-

É este o pouco então que ofereces, simplórias

Gotas d'água, somente este vinho infecundo?

\section{$1^{\text {a }}$ estrofe}


ca, há uma quebra dos 6/6 no quarto verso, porém mantendo o acento na sexta sílaba. As rimas são cruzadas $(\mathrm{AB} / \mathrm{AB})$, com os três primeiros versos divididos em dois hemistíquios (6/6), sendo que o quarto verso está dividido em $4 / 8$, recurso que se repetirá no último verso do dístico. Percebe-se também o enjambement. Na tradução, o respeito à métrica foi um dos fatores limitantes na escolha das palavras. No caso do segundo hemistíquio do primeiro verso, uma palavra teve de ser inserida para contemplá-la. A opção por "lua fria" harmoniza-se com o sentido geral da estrofe, pois se o sol não aquece, que dirá a lua?

No verso "Que sugas ao fundo de teu calado mundo?" havia a opção de traduzir por "Que sugas ao fundo desse teu surdo mundo?". Sugas e surdo formariam uma aliteração e as repetições do som da vogal " $u$ " também seriam reforçadas. O problema estava em usar o pronome "desse" como artifício, pois mais adiante, no quarto verso, seria obrigada a usar tal recurso novamente para fechar a métrica. Escolhi a palavra "calado", pois esse vocábulo, além de significar "mudo" ou "que não fala", também traz em si a noção de profundidade, visto que é a distância entre a parte inferior da quilha de uma embarcação e a linha de flutuação - o que era apropriado, já que esse verso dá a idéia de algo que é drenado, sugado, aspirado para as profundezas.

No terceiro verso, poucas eram as opções de rima para "memória". Escolhi "simplórias", pois com o enjambement, a palavra escolhida seria adjetivo de "gotas d'água". O vocábulo "simplório" não tem o sentido de simples, mas de tolo, ingênuo, crédulo. No entanto, resolvi tomar essa liberdade. A palavra inexiste no original, mas não creio que deturpe o sentido geral da estrofe. A escolha de "infecundo" também é uma tentativa de transcriação. Quanto à métrica, a tradução manteve a quebra (4/8) do quarto verso. 


\section{$2^{\mathbf{a}}$ estrofe}

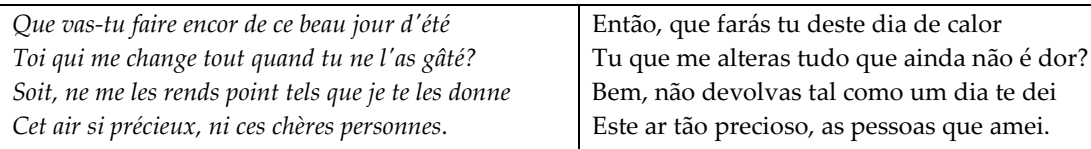

Na segunda estrofe, há uma aceitação da condição da memória. O poeta pergunta o que ela fará do belo dia de hoje: o esquecerá, o guardará em algum canto? Ele pede a ela que não devolva nem as pessoas queridas, nem a atmosfera desse dia único, talvez porque essa "devolução", em forma de lembrança, nunca será o mesmo que o vivido no presente. Escolhi "calor" e não "verão" porque as rimas em "ão" são pobres, e precisaria lançar mão delas na estrofe seguinte. Porém, não pude evitar outras rimas igualmente pobres como "calor/dor" e dei/amei. Consola o fato de que no original essas rimas também são simples: été/gâté, donne/personnes; no entanto, elas rimam substantivo com verbo, enquanto que na tradução estão rimadas palavras da mesma classe gramatical.

\section{$3^{\text {a }}$ estrofe}

\begin{tabular}{l|l} 
Que modèlent mes jours ta lumière et tes mains, & Que moldam os meus dias tua luz e tuas mãos, \\
Refais par-dessus moi les voies du lendemain, & Refaz por sobre mim as vias dos que virão, \\
Et mène-moi le coeur dans les champs de vertige & Leva meu coraça por campos de vertigem \\
Où l'herbe n'est plus l'herbe et doute sur sa tige & Onde até o gramado duvida de sua origem
\end{tabular}

Na terceira estrofe, há um resgate da memória vista por um novo ângulo. Apresenta a idéia de memória não no sentido de ir "em busca de um tempo perdido", mas sim, como construtora do futuro, como se lê no segundo verso "Refais par-dessus moi les voies du lendemain". A memória também constrói o futuro, e está nessa estrofe a ideia do futuro como desconhecido, inusitado. A imagem do coração guiado por campos de vertigem traz a ideia-sensação do novo que causa vertigem. Embora as coisas não sejam mais como 
antes, não há saudosismo aí. Ao contrário, há mesmo uma atração pela construção do futuro. Ou seja, o trabalho da memória é valorizado, e o dístico é conciliatório:

\section{Dístico}

Mais de quoi me plaignais-je, ô légère mémoire... Mas de que reclamo, ó leve reviver..

Afinal, de que se queixa o poeta, já que apesar das "falhas" ou das "limitações" da memória, todos temos sede de relembrar, todos queremos beber dessa fonte?

\section{Soneto II}

O segundo soneto fala das contradições da memória, que muda os acontecimentos e, às vezes, transforma em dor o que originalmente foi prazer (talvez pelo simples fato de o prazer já ter se extinguido temporalmente). O tema da primeira estrofe do primeiro soneto é aprofundado. Cada vez que o poeta abre seu "armário escondido das lembranças", sente-se confuso. A memória degrada as cores do que foi vivido. O sentido privilegiado nessa estrofe é a visão, e "secrètes armoires" é metáfora do inconsciente, lugar onde lembranças e imaginação se confundem. Deve-se observar que há uma quebra da métrica no primeiro verso (3/9).

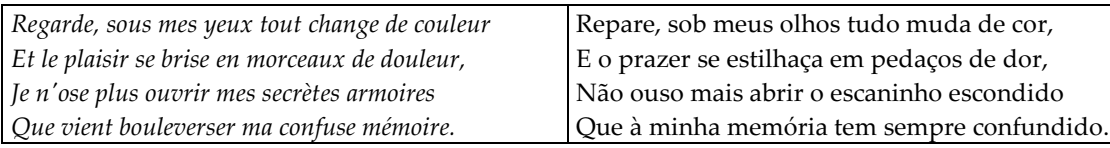

A segunda estrofe trata do espírito um tanto brincalhão da memória, que gosta de mudar ou transformar (adulterar?) as coisas. Também se percebe duas das características da poesia de Supervielle: as metamorfoses e o zoomorfismo. Pássaros, abelhas e focinhos povoam a estrofe. E, no último verso, o poeta começa a falar sobre o 
fato de a memória nunca dar o que se quer dela. $\mathrm{O}$ paralelismo das orações é marcante.

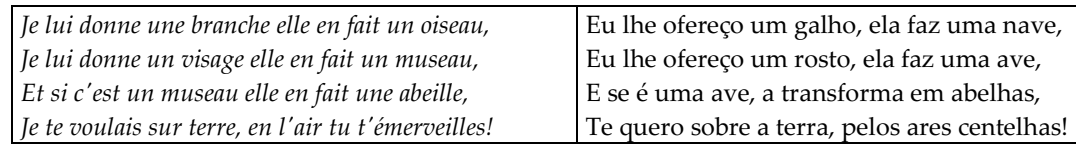

Para ser fiel ao zoomorfismo, o ideal seria não usar a palavra "nave", mas sim o nome de um animal ou de parte dele, mas não foi encontrada solução melhor. Já a opção de traduzir "t'émerveilles" por "centelhas" é interessante, pois o vocábulo em francês tem o sentido de "maravilhar", e "centelhar" é "faiscar", "cintilar", "luzir", o que torna a imagem poética ainda mais dinâmica.

A terceira estrofe prossegue com a ideia iniciada no último verso da anterior. Explora o fato de não podermos controlar como e nem quando as lembranças chegam até nossa consciência. Simplesmente, nunca lembramos como gostaríamos. Se queremos lembrar, esquecemos. Se queremos esquecer, recordamos. $\mathrm{O}$ movimento de transformação escapa ao poeta. A anteposição das idéias e o paralelismo das orações permanecem.

O par de versos finais questiona o que a memória fez das coisas belas, dos sentimentos bons, sugerindo, talvez, que foram sugadas para os domínios do pâle soleil d'oubli. 
Marlova G. Aseff. Sobre a tradução de Oublieuse mémoire, de Jules Supervielle

\section{Soneto III}

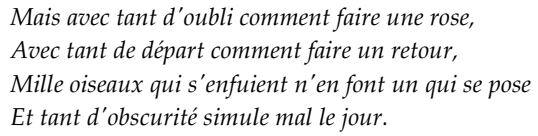

Com tanto esquecimento, como fazer um poema? Tudo se perde com o tempo, não há como recompor o passado. De novo, os pássaros retornam ao verso para marcar a intangibilidade da vida. Na tradução, para manter a palavra "rosa", uma metáfora de poe$\mathrm{ma}$, foi preciso fazer uma rima imperfeita (rosa/pousa). $\mathrm{O}$ trecho faz lembrar "El poema", do poeta espanhol Juan Ramón Jiménez, que diz: “No le toques ya más/ que así es la rosa!" A rosa como símbolo de perfeição, mistério e efemeridade, assim como o poema para os modernistas hispano-americanos.

Em seguida, o poeta prossegue com as metáforas do voo iniciadas na estrofe anterior. Confere leveza e certa excitação que prosseguirá nos quartetos finais. Os sentidos reforçados são a audição e a visão. No original, o poeta repete a palavra "joue", com sentido de "face" e de "brincar". Na tradução, optei por usar "sombria" e "sombra".

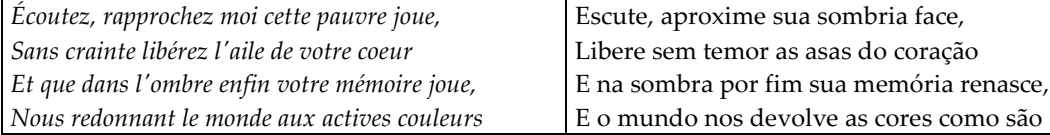

Na terceira estrofe, a natureza aparece em um momento mítico de criação. A árvore renasce e um lago surge do solo. Na tradução, tentei manter o sentido e recriar as rimas internas do primeiro verso. Ao invés de rimas internas, criei aliterações: chêne /plaine - arbre/ ombres tornaram-se seco/nascente - brota/transborda. 


\begin{tabular}{|l|l|}
\hline Le chêne redevient arbre et les ombres, plaine, & O tronco seco brota, e a nascente transborda \\
Et voici donc ce lac sous nos yeux agrandis? & E eis então este lago sob olhos espantados? \\
Que jusqu'à l'horizon la terre se souvienne & Que até o firmamento sei que a terra recorda \\
Et renaisse pour ceux qui s'en croyaient bannis! & E renasce por quem se cria renegado! \\
\end{tabular}

\section{Quartetos finais}

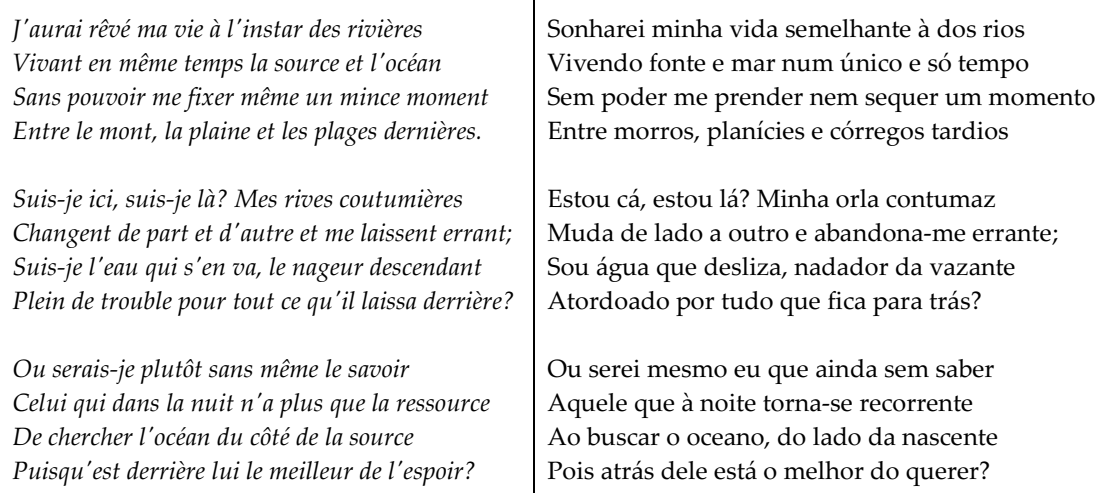

Sonharei minha vida semelhante à dos rios Vivendo fonte e mar num único e só tempo Sem poder me prender nem sequer um momento Entre morros, planícies e córregos tardios

Estou cá, estou lá? Minha orla contumaz Muda de lado a outro e abandona-me errante; Sou água que desliza, nadador da vazante Atordoado por tudo que fica para trás?

Ou serei mesmo eu que ainda sem saber Aquele que à noite torna-se recorrente Ao buscar o oceano, do lado da nascente Pois atrás dele está o melhor do querer?

Os quartetos finais trazem as mais belas imagens dos quatro poemas, causando intenso prazer estético. Conforme Bachelard (1990, p. 2), “o poema é essencialmente uma aspiração a imagens novas", e esses versos estão repletos delas. As metáforas com a água em movimento dominam. Rios, mar, oceano, fonte, praias, nadador, água que desliza. Podemos sentir uma qualidade de "ligeireza" a partir dessas imagens. Denotam o caráter móvel, mutante da vida que se transforma como a água da nascente que segue pelos rios até encontrar o oceano. A vida segue seu curso no ritmo da correnteza, e o poeta se atordoa, por um momento, ao pensar no que ficou para trás: fatos e pessoas que pertencem somente ao domínio da memória. Ao mesmo tempo, se conforma com essa contingência da existência. 
Marlova G. Aseff. Sobre a tradução de Oublieuse mémoire, de Jules Supervielle

\section{Referências}

BACHELARD, Gaston. O ar e os sonhos. Tradução de Antonio Danesi. São Paulo: Martins Fontes, 1990.

BLANCHOT, Maurice. "Oblieuse mémoire", in La Nouvelle Revue Française, n. 94, p. $747,1960$.

BILAC, Olavo. "Sonho", in Nossos clássicos - Olavo Bilac. Seleção de Alceu Amoroso Lima. Rio de Janeiro: Editora Agir, p. 63, 1963.

BRANDO. Óscar. "Jules Supervielle", in OREGGIONI, Alberto (org). Nuevo Diccionario de Literatura Uruguaya. Montevideo: Banda Oriental, 2001.

CUNHA, Celso e CINTRA, Lindley. Nova gramática do português contemporâneo. Rio de Janeiro: Editora Nova Fronteira, 1985.

DEWULF, Sabine. Jules Supervielle ou la connaissance poétique. Coll. Critiques littéraires. Paris: L'Harmattan, 2001.

GLEDSON, John. "Drummond e Supervielle", in Influências e impasses: Drummond e alguns contemporâneos. Tradução de Frederico Dantello. São Paulo: Companhia das Letras, 2003.

GRAMMONT, Maurice. Petit traité de versification française. Paris: Librairie Armand Colin, 1951.

KADDOUR, Hédi. "Réflexion sur un titre", in Europe, revue littéraire mensuelle, abril, nº 792, p. 60-61, 1995.

MALÉZIEUX PASTOL, D. “Oublieuse mémoire”, in Dictionnaire des Oeuvres littéraires de langue française. Paris: Bordas, 1994.

ROY, Claude. Jules Supervielle. Collection Poètes d'aujourd'hui. Paris: Editions Pierre Seghers, 1953.

SUHAMY, Henri. La poétique. Collection Que sais-je?. Paris: Presses Universitaires de France, 1986.

SUPERVIELLE, Jules. "En songeant à un art poétique", in Naissances. Paris: Gallimard, 1951.

. La fable du monde. Paris: Gallimard, 1938. 
Cadernos de Literatura em Tradução, n. 11, p. 93-110

Memória infiel $^{8}$
I
Pálido sol de olvido, lua fria da memória,
Que sugas tu ao fundo de teu calado mundo?
É este o pouco então que ofereces, simplórias
Gotas d'água, somente este vinho infecundo?
Então, que farás tu deste dia de calor
Tu que me alteras tudo que ainda não é dor?
Bem, não devolvas tal como um dia te dei
Este ar tão precioso, as pessoas que amei.
Que moldam os meus dias tua luz e tuas mãos,
Refaz por sobre mim as vias dos que virão,

Leva meu coração por campos de vertigem

Onde até o gramado duvida de sua origem.

Mas eu de que reclamo, ó leve reviver...

Quem teve sede? Quem não queria beber?

II

Oublieuse mémoire

I

Pâle soleil d'oubli, lune de la mémoire,

Que draines-tu au fond de tes sourdes contrées?

Est-ce donc là ce peu que tu donnes à boire

Ces gouttes d'eau, le vin que je te confiai?

Que vas-tu faire encor de ce beau jour d'été

Toi qui me change tout quand tu ne l'as gâté?

Soit, ne me les rends point tels que je te les donne

Cet air si précieux, ni ces chères personnes.

Que modèlent mes jours ta lumière et tes mains, Refais par-dessus moi les voies du lendemain,

Et mène-moi le coeur dans les champs de vertige

Où l'herbe n'est plus l'herbe et doute sur sa tige.

Mais de quoi me plaignais-je, ô légère mémoire...

Qui avais soif ? Quelqu'un ne voulait-il pas boire?

Repare, sob meus olhos tudo muda de cor, E o prazer se estilhaça em pedaços de dor,

Não ouso mais abrir o escaninho escondido

Que à minha memória tem sempre confundido.

Eu lhe ofereço um galho, ela faz uma nave,

Eu lhe ofereço um rosto, ela faz uma ave,

E se é uma ave, a transforma em abelhas,

Te quero sobre a terra, pelos ares centelhas!

Retiro-te da cama, já estás bem distante,

Escondo-te num canto e tu arrombas a porta, Tenho-te contra mim, és não mais que uma morta,

Desejo-te em silêncio, tu cantas saltitante.

Que fizeste da torre que um dia eu te dei

E que fez da afeição teu coração sem lei?

Regarde, sous mes yeux tout change de couleur Et le plaisir se brise en morceaux de douleur,

Je n'ose plus ouvrir mes secrètes armoires

Que vient bouleverser ma confuse mémoire.

Je lui donne une branche elle en fait un oiseau,

Je lui donne un visage elle en fait un museau,

Et si c'est un museau elle en fait une abeille,

Je te voulais sur terre, en l'air tu t'émerveilles!

Je te sors de ton lit, te voilà déjà loin,

Je te cache en un coin et tu pousses la porte,

Je te serrais en moi, tu n'es plus qu'une morte,

Je te voulais silence et tu chantes sans fin.

Qu'as-tu fais de la tour qu'un jour je te donnai

Et qu'a fait de l'amour ton coeur désordonné?

8 Esta tradução, sem o comentário, foi publicada pela revista Novos Estudos Cebrap, n. 75 julho de 2006. 
Marlova G. Aseff. Sobre a tradução de Oublieuse mémoire, de Jules Supervielle

\begin{tabular}{|l|l|}
\hline III & III
\end{tabular}

Mas com tanto esquecer, como se faz a rosa, Com tantas despedidas, como irei retornar, Mil pássaros em fuga, nenhum por aqui pousa Em tanta escuridão, mal pode o dia vingar.

Escute, aproxime sua sombria face,

Libere sem temor as asas do coração

E na sombra por fim sua memória renasce,

E o mundo nos devolve as cores como são

O tronco seco brota, e a nascente transborda E eis então este lago sob olhos espantados? Que até o firmamento sei que a terra recorda

E renasce por quem se cria renegado!

Memória, irmã obscura que olho na face,

Desde que me permita uma imagem que passe...

IV

Sonharei minha vida semelhante à dos rios Vivendo fonte e mar num único e só tempo Sem poder me prender nem sequer um momento Entre morros, planícies e córregos tardios

Estou cá, estou lá? Minha orla contumaz Muda de lado a outro e abandona-me errante; Sou água que desliza, nadador da vazante Atordoado por tudo que fica para trás?

Ou serei mesmo eu que ainda sem saber Aquele que à noite torna-se recorrente Ao buscar o oceano, do lado da nascente Pois atrás dele está o melhor do querer?
Mais avec tant d'oubli comment faire une rose, Avec tant de départ comment faire un retour, Mille oiseaux qui s'enfuient n'en font un qui se pose Et tant d'obscurité simule mal le jour.

Écoutez, rapprochez moi cette pauvre joue, Sans crainte libérez l'aile de votre coeur Et que dans l'ombre enfin votre mémoire joue, Nous redonnant le monde aux actives couleurs

Le chêne redevient arbre et les ombres, plaine, Et voici donc ce lac sous nos yeux agrandis? Que jusqu'à l'horizon la terre se souvienne Et renaisse pour ceux qui s'en croyaient bannis!

Mémoire, soeur obscure et que je vois de face Autant que le permet une image qui passe ...

IV

J'aurai rêvé ma vie à l'instar des rivières Vivant en même temps la source et l'océan Sans pouvoir me fixer même un mince moment Entre le mont, la plaine et les plages dernières.

Suis-je ici, suis-je là? Mes rives coutumières Changent de part et d'autre et me laissent errant; Suis-je l'eau qui s'en va, le nageur descendant Plein de trouble pour tout ce qu'il laissa derrière?

Ou serais-je plutôt sans même le savoir Celui qui dans la nuit n'a plus que la ressource De chercher l'océan du côté de la source Puisqu'est derrière lui le meilleur de l'espoir? 